\title{
A Novel Paclitaxel Microemulsion Containing a Reduced Amount of Cremophor EL: Pharmacokinetics, Biodistribution, and In Vivo Antitumor Efficacy and Safety
}

\author{
Ying Wang, ${ }^{1,2}$ Ke-Chun Wu, ${ }^{1}$ Bing-Xiang Zhao, ${ }^{1}$ Xin Zhao, ${ }^{1}$ Xin Wang, ${ }^{1}$ Su Chen, \\ Shu-Fang Nie, ${ }^{2}$ Wei-San Pan, ${ }^{2}$ Xuan Zhang, ${ }^{1}$ and Qiang Zhang ${ }^{1,3}$ \\ ${ }^{1}$ Department of Pharmaceutics, School of Pharmaceutical Sciences, Peking University, Beijing 100191, China \\ ${ }^{2}$ Department of Pharmaceutics, School of Pharmacy, Shenyang Pharmaceutical University, 103 Wenhua Road, \\ Shenyang 110016, China \\ ${ }^{3}$ State Key Laboratory of Natural and Biomimetic Drugs, School of Pharmaceutical Sciences, Peking University, Beijing 100191, China
}

Correspondence should be addressed to Xuan Zhang, xuanzhang18@163.com

Received 2 August 2010; Revised 23 October 2010; Accepted 16 December 2010

Academic Editor: Mark J. McKeage

Copyright (c) 2011 Ying Wang et al. This is an open access article distributed under the Creative Commons Attribution License, which permits unrestricted use, distribution, and reproduction in any medium, provided the original work is properly cited.

\begin{abstract}
The purpose of this study was to prepare a novel paclitaxel (PTX) microemulsion containing a reduced amount of Cremophor EL (CrEL) which had similar pharmacokinetics and antitumor efficacy as the commercially available PTX injection, but a significantly reduced allergic effect due to the CrEL. The pharmacokinetics, biodistribution, in vivo antitumor activity and safety of PTX microemulsion was evaluated. The results of pharmacokinetic and distribution properties of PTX in the microemulsion were similar to those of the PTX injection. The antitumor efficacy of the PTX microemulsion in OVCRA-3 and A 549 tumor-bearing animals was similar to that of PTX injection. The PTX microemulsion did not cause haemolysis, erythrocyte agglutination or simulative reaction. The incidence and degree of allergic reactions exhibited by the PTX microemulsion group, with or without premedication, were significantly lower than those in the PTX injection group $(P<.01)$. In conclusion, the PTX microemulsion had similar pharmacokinetics and anti-tumor efficacy to the PTX injection, but a significantly reduced allergic effect due to CrEL, indicating that the PTX microemulsion overcomes the disadvantages of the conventional PTX injection and is one way of avoiding the limitations of current injection product while providing suitable therapeutic efficacy.
\end{abstract}

\section{Introduction}

Paclitaxel (PTX) is one of the most important compounds which has recently been obtained from a natural source [1]. It is approved for the treatment of ovarian, breast, nonsmall cell lung carcinomas and AIDS-related Kaposi's sarcoma. The currently available pharmaceutical formulation of PTX (such as Taxol, Bristol-Myers Squibb, New York, NY, USA) contains $30 \mathrm{mg}$ PTX dissolved in $5 \mathrm{~mL} \mathrm{50 \%}$ Cremophor EL (polyethoxylated castor oil, CrEL) and 50\% dehydrated ethanol $(1: 1, \mathrm{v} / \mathrm{v})$ to enhance the solubility of PTX in water. However, a large number of studies have reported various side effects of CrEL, such as hypersensitivity, neurotoxicity, and neuropathy $[2,3]$. Therefore, premedication is mandatory before paclitaxel administration. The premedication schedule includes corticosteroids, diphenhydramine or chlorpheniramine, $\mathrm{H}_{2}$-receptor antagonists and antiemetics. Despite such premedication, minor reactions (flushing and rash) still occur in $41-44 \%$ of all patients and major, potentially life threatening, reactions in 1.5-3\% [4-6]. Although CrEL has been used to administer other drugs, such as cyclosporine and teniposide, the amount of CrEL necessary to deliver the required doses of Taxol is significantly higher than that used with any other commercially available drugs [2].

Therefore, current approaches to improve this situation are focused mainly on the development of formulations that contain no CrEL. These strategies include increasing the aqueous solubility of PTX by cosolvency, emulsification, microemulsification, drug complexation with cyclodextrins, carrier mediation using liposomes, nanoparticles, and structural modification to obtain analogues and prodrugs [7]. 
It has been reported that some CrEL-free or reduced CrEL PTX formulations, such as Genexol-PM, AI-850, or Genetaxyl, have been developed and evaluated in clinical trials [8-11]. Now, a novel CrEL-free albumin-bound nanoparticle formulation of PTX (ABI-007) has been approved by the US Food and Drug Administration for pretreated metastatic breast cancer patients. This formulation is prepared by highpressure homogenization of PTX in the presence of serum albumin, resulting in a nanoparticle colloidal suspension. The albumin concentration is $3-4 \%$, which is similar to the albumin concentration in blood [12].

Microemulsions are isotropic, thermodynamically stable transparent (or translucent) systems of oil, water, and surfactant, frequently in combination with a cosurfactant with a droplet size usually in the range of $20-200 \mathrm{~nm}[13,14]$. The combination of surfactants with oils to form microemulsions offers an advantage over a micellar or cosolvent system in terms of the drug solubilization capacity for lipophilic compounds, because of the extra solubilization provided by the oil phase [15]. Also, because of the small droplet diameter, microemulsions can be sterilized by filtration [16]. The obvious benefits of microemulsions as drug delivery systems have led to the development of several systems for intravenous administration of PTX in recent years. Recently, two CrEL-free paclitaxel microemulsions were developed for intravenous administration [17, 18]. In fact, most PTX microemulsions for intravenous administration contain CrEL.

Although PTX was first discovered in the early 1960s, its clinical development were delayed until the early 1980s, one reason being its poor solubility. After much investigation, CrEL, and dehydrated ethanol USP $(1: 1, \mathrm{v} / \mathrm{v})$ was identified as the most suitable option for the solvent system employed in the commercial formulation of PTX, Taxol [19]. Until now, although several reports have linked this solvent to alterations in the pharmacokinetic profile of PTX and the production of side effects, CrEL is still used as an excipient for Taxol.

In the present study, a novel PTX microemulsion containing a reduced amount of CrEL was prepared. The pharmacokinetics and biodistribution of this PTX microemulsion were investigated in rats. The in vivo antitumor activity of the PTX microemulsion was evaluated in tumor-bearing mice and the safety of the PTX microemulsion was also evaluated.

\section{Material and Methods}

2.1. Materials. PTX and docetaxel were obtained from MeiLian Co. Ltd. (Chongqing, China). Cremophor EL (CrEL) was purchased from BASF Corporation of Germany (Local Agent in Shanghai, China). Egg phosphatidylcholine (Lipoid E 80) was obtained from Lipoid GmbH (Local Agent Shanghai Toshisun Enterprise Co., Ltd in Shanghai, China). PTX injection was commercially available from a local hospital in Beijing (Taxol, Bristol Myers Squibb Co., Princeton, NJ, USA, for pharmacokinetic and biodistribution experiments; PTX injection, Beijing Shiqiao Biological Pharmaceutical Co., Ltd., Beijing, China, for antitumor and allergic reaction experiments), and the PTX injection formulation contained
$30 \mathrm{mg}$ PTX in $5 \mathrm{~mL} 50 \% \mathrm{CrEL}(\mathrm{v} / \mathrm{v})$ and 50\% dehydrated ethanol $(\mathrm{v} / \mathrm{v})$. Medical products for premedication were also commercially available from a local hospital in Beijing. All other chemicals were of analytical grade or HPLC grade.

2.2. Animals and Cell Lines. Sprague-Dawley (SD) rats weighing $200 \pm 20 \mathrm{~g}$, New Zealand albino rabbits weighing $1.8-2.0 \mathrm{~kg}$ and beagle dogs weighing $8-12 \mathrm{~kg}$ were all obtained from the Experimental Animal Center of Peking University Health Science Center. Female BALB/C nude mice weighing 18-22 g (6-8 weeks) were purchased from the Academy of Military Medical Sciences. All care and handling of animals were performed in accordance with the Institutional Authority for Laboratory Animal Care of Peking University.

A human ovarian cancer cell line (OVCAR-3) and a human nonsmall-cell lung cancer cell line (A 549) were obtained from ATCC.

2.3. Preparation of PTX the Microemulsion. The PTX microemulsion used in the experiment was prepared in our laboratory with some modification of the published method [20]. In brief, to prepare PTX microemulsion concentrated solution, PTX was dissolved in dehydrated alcohol and then mixed with Lipoid E 80, CrEL and soybean oil. When this concentrated solution was mixed with 5\% glucose infusion, it underwent self-emulsification to form a PTX microemulsion.

2.4. Physicochemical Characterization of the PTX Microemulsion. The volume of $5 \%$ glucose solution used for diluting the PTX concentration solution was $24 \mathrm{~mL}$ (the final concentration of PTX in microemulsion was $1 \mathrm{mg} / \mathrm{mL}$ ). For particle size analysis, this microemulsion was further diluted with $5 \%$ glucose solution to a concentration of PTX about $0.03 \mathrm{mg} / \mathrm{mL}$. The particle size of the PTX microemulsion was measured by photon correlation spectroscopy using Malvern Zeta sizer nano-ZS instrument (Malvern, UK) at $25^{\circ} \mathrm{C}$. The morphological examination of PTX microemulsions was performed on a JEOL JEM-200CX instrument at an acceleration voltage of $200 \mathrm{kV}$ by transmission electron microscope (TEM). Briefly, the TEM samples were prepared by dropping one drop of PTX microemulsion (about $0.03 \mathrm{mg} / \mathrm{mL}$, PTX concentrated solution was diluted with $5 \%$ glucose solution) onto a 300-mesh Formvar-coated copper grid. The grids were negatively stained at room temperature with freshly prepared and sterile-filtered $2 \%(\mathrm{w} / \mathrm{v})$ uranyl acetate aqueous solution. The grids were washed twice and air dried prior to imaging.

2.5. Pharmacokinetic Studies. Ten SD male rats were randomly divided into two groups of five rats. All the animals were fasted for $12 \mathrm{~h}$ prior to the experiments. PTX injection or microemulsion concentrated solution was diluted with $5 \%$ glucose injection at a concentration of $1 \mathrm{mg} / \mathrm{mL}$, respectively. These PTX formulations were all injected into the tail vein at a single dose of $5 \mathrm{mg} / \mathrm{kg}$. Blood samples $(0.5 \mathrm{~mL})$ were collected via the orbital venous plexus at $0,0.17,0.33,0.67$, $1,1.5,2,3,4,6$, and $8 \mathrm{~h}$ after injection. After centrifugation 
at $3000 \mathrm{~g}$ for $5 \mathrm{~min}$, the obtained plasma was stored at $-20^{\circ} \mathrm{C}$ until required for determination.

2.6. Biodistribution Studies. Twenty-four female rats were randomly divided into two groups. PTX injection or microemulsion concentrated solution was diluted with $5 \%$ glucose injection at a concentration of $1 \mathrm{mg} / \mathrm{mL}$. These PTX formulations were all given intravenously via the tail vein at a dose of $5 \mathrm{mg} / \mathrm{kg}$. After drug administration, rats were exsanguinated through the femoral artery at $0.167,1,4$, and $8 \mathrm{~h}$ (three rats for each time point). The heart, liver, spleen, lung, kidney, brain, and ovaries were collected. Tissue samples were blotted with paper towel, rinsed in saline, blotted to remove excess fluid, weighed, and stored at $-20^{\circ} \mathrm{C}$.

2.7. In Vivo Antitumor Efficacy. The female BALB/C nude mice were inoculated subcutaneously in the right flank with $0.1 \mathrm{~mL}$ of an OVCAR-3 cell suspension $\left(4 \times 10^{6}\right)$. Administration was started at day 14 after inoculation when the tumor size reached approximately $150 \mathrm{~mm}^{3}$. On that day, mice were randomly divided into a control group, a PTX injection treatment group, and a PTX microemulsion treatment group. Each group consisted of 6 tumor-bearing mice. In another separate study, a solid tumor was established following S.C. injection of $0.1 \mathrm{~mL}$ of an A549 cell suspension $\left(5 \times 10^{6}\right)$ into the right flank of the mice. Treatments were started when the tumor size reached approximately $150 \mathrm{~mm}^{3}$, about 7 days after inoculation. On that day, mice were randomly divided into a control group, a PTX injection treatment group and a PTX microemulsion treatment group. Each group consisted of 6 tumor-bearing mice.

In the antitumor activity experiment, PTX injection or microemulsion concentrated solution was diluted with 5\% glucose infusion to give a concentration of $1.5 \mathrm{mg} / \mathrm{mL}$. Each group was treated with $5 \%$ glucose infusion, PTX injection ( $15 \mathrm{mg} / \mathrm{kg}$, i.v., q4d4, every 4 days for four doses), or PTX microemulsion $(15 \mathrm{mg} / \mathrm{kg}$, i.v., q4d4, every 4 days for four doses), respectively. Formulations were given intravenously via the tail vein. Throughout the study, mice were weighed and tumors were measured with calipers twice a week. Tumor volumes were calculated from the formula: $\mathrm{V}=$ length $(\mathrm{cm})$ $\times$ width $\left(\mathrm{cm}^{2}\right) \times 0.5236$. Once an animal in any group died, all the other animals in the experiment were sacrificed.

2.8. Intravenous Injection Safety Assessment. Hemolysis test: rabbit blood was used to test the hemolytic effect of the PTX microemulsion. Briefly, $10 \mathrm{~mL}$ rabbit blood was obtained from the arteria cruralis and the fibrinogen was removed by stirring with a glass rod. Then, 10 milliliter $5 \%$ glucose infusion was added to the fibrinogen-free blood sample and supernatant was removed after centrifugation at $3000 \mathrm{rpm}$ for $5 \mathrm{~min}$. The erythrocyte pellet at the bottom of centrifuge tube was washed four times (centrifugation followed by redispersion) with $5 \%$ glucose infusion. Finally, after repeated washing and centrifugation, a suitable amount of $5 \%$ glucose infusion was added to the erythrocyte pellet to give a $2 \%$ erythrocyte standard dispersion which was stored at $4^{\circ} \mathrm{C}$. The PTX microemulsion concentrated solution was diluted with
$5 \%$ glucose infusion to give a concentration of $1 \mathrm{mg} / \mathrm{mL}$, and different amounts of microemulsion in volumes of $0,0.1$, $0.2,0.3,0.4$, and $0.5 \mathrm{~mL}$ were added to six tubes each tube containing $2.5 \mathrm{~mL} 2 \%$ erythrocyte dispersion. Then, suitable amounts of $5 \%$ glucose infusion were added to every tube to obtain a final volume of $5 \mathrm{~mL}$. A positive control was prepared by addition of $2.5 \mathrm{~mL}$ distilled water to $2.5 \mathrm{~mL} 2 \%$ erythrocyte dispersion instead of $5 \%$ glucose infusion. After vortexing, the tubes were incubated at $37^{\circ} \mathrm{C}$ and observed microscopically from $15 \mathrm{~min}$ to $4 \mathrm{~h}$.

Intravenous irritation assessment: one male and two female rabbits weighing $1.8-2.0 \mathrm{~kg}$ were used for this study. PTX microemulsion concentrated solution was diluted with $5 \%$ glucose infusion to give a concentration of $1 \mathrm{mg} / \mathrm{mL}$. Each rabbit (three animals) received a daily dose of $5 \mathrm{mg} / \mathrm{kg}$ PTX microemulsion into the vein at the edge of the left ear at an injection rate of $1 \mathrm{~mL} / \mathrm{min}$ for 3 days. An equivalent volume of $5 \%$ glucose infusion was injected into the right ear-border vein of these three animals as a control. After injection, the reaction at the injection site was recorded. The rabbits were sacrificed by exsanguination $24 \mathrm{~h}$ after the last administration, and the ears were cut and fixed in $10 \%$ formaldehyde for histological examination. At sites $3 \mathrm{~cm}$ from the injection site to the proximal part, histological sections were prepared for histopathological examination.

Allergic reaction: in the allergic reaction experiment, PTX injection or microemulsion concentrated solution was diluted with $5 \%$ glucose infusion to give a concentration of $0.6 \mathrm{mg} / \mathrm{mL}$. The beagle dogs were divided into five groups $(n=6)$ : a control group, a PTX injection treatment group, a PTX microemulsion treatment group, a PTX injection premedication treatment group, and a PTX microemulsion premedication treatment group. In the control group, animals were given $5 \%$ glucose by infusion. In the PTX formulation treatment groups, the diluted PTX formulations were administered by infusion at a dosage of $165 \mathrm{mg} / \mathrm{m}^{2}$ $(8.25 \mathrm{mg} / \mathrm{kg})$. Infusion was initiated at a rate of $30 \mathrm{~mL} / \mathrm{h}$ for 10 minutes. If no allergic reaction was noted in the first 10 minutes, the rate of infusion was increased to $60 \mathrm{~mL} / \mathrm{h}$ for 10 additional minutes, and if no reaction was noted, it was increased again to $90 \mathrm{~mL} / \mathrm{h}$ for the rest of the infusion. The total infusion time was between 3 and 6 hours. In the premedication groups, the animals were initially premedicated with prednisone $(1 \mathrm{mg} / \mathrm{kg} \mathrm{PO})$, diphenhydramine $(4 \mathrm{mg} / \mathrm{kg}$ IM), cimetidine ( $4 \mathrm{mg} / \mathrm{kg} \mathrm{IV})$, and dexamethasone Na Phos ( $2 \mathrm{mg} / \mathrm{kg} \mathrm{IV)} \mathrm{according} \mathrm{to} \mathrm{a} \mathrm{previous} \mathrm{report} \mathrm{[21],} \mathrm{and} \mathrm{then}$ they received the PTX formulations by infusion as the PTX formulation treatment groups. The allergic reactions exhibited by the animals were observed and ranked according to Table 1. After administration, animals were continuously monitored for at least 14 days to further evaluate their mental state, food intake, and defecation. The body weights were recorded on day 4,8 , and 12 , and full blood cell counts were carried out on day 4 and 8 .

2.9. Measurement of PTX in Plasma, Blood, and Tissues. PTX was measured in plasma and blood according to a previous report [22]. Briefly, an aliquot of $100 \mu \mathrm{l}$ plasma (or blood), $50 \mu \mathrm{l}$ docetaxel solution $(10 \mu \mathrm{g} / \mathrm{mL}$, as an internal standard), 
TABLE 1: The severity of allergic reactions.

\begin{tabular}{lccc}
\hline Grade $1 /+$ & Grade 2/++ & Grade 3/+++ & Grade 4/++++ \\
\hline Mania & Drowsiness & Angioedema & Life-threatening \\
Licking nose & Rash/flushing/urticaria & Gatism & Death \\
Transient flushing or rash & Mucous membrane hyperemia & Vomiting & \\
Head shaking & Dyspnea & & \\
\hline
\end{tabular}

and $2.5 \mathrm{~mL}$ acetonitrile were mixed using a vortex mixer for $30 \mathrm{~s}$. The mixture was centrifuged at $3000 \mathrm{~g}$ for $10 \mathrm{~min}$, then $2.0 \mathrm{~mL}$ supernatant was collected, and dried under a gentle stream of nitrogen gas at $50^{\circ} \mathrm{C}$ in a water bath. The residue was reconstituted using the mobile phase below, and assayed by HPLC using a Waters system consisting of a 1525-pump, and a 2487-ultraviolet detector (Waters Co., Inc., Westerville, $\mathrm{OH}, \mathrm{USA})$. The mobile phase consisted of methanol-watertetrahydrofuran $(70: 27.5: 2.5, \mathrm{v} / \mathrm{v} / \mathrm{v})$ delivered at a flow rate of $1 \mathrm{~mL} / \mathrm{min}$. Chromatographic separation was performed on a Phenomenex $\mathrm{ODS}_{3}$ column $(250 \times 4.6 \mathrm{~mm}, 5 \mathrm{~mm}$, Torrance, CA, USA), and the detector wavelength was set at $230 \mathrm{~nm}$. The peak areas of PTX (Ap) and docetaxel (Ad) were recorded, and the concentration of PTX was calculated from the ratio of $\mathrm{Ap} / \mathrm{Ad}$.

Tissue concentrations of PTX were also determined by HPLC. Briefly, tissue samples were homogenized in saline and the homogenate $(0.7 \mathrm{~mL})$ was mixed with $50 \mu$ l docetaxel solution $(10 \mu \mathrm{g} / \mathrm{mL}$, as an internal standard), and $2.5 \mathrm{~mL}$ acetonitrile. After vortex mixing for $30 \mathrm{~s}$, the mixture was centrifuged at $3000 \mathrm{~g}$ for $10 \mathrm{~min}, 2.0 \mathrm{~mL}$ supernatant was collected, and dried under a gentle stream of nitrogen gas at $50^{\circ} \mathrm{C}$ in a water bath. The residue was reconstituted using the mobile phase and then determined by HPLC as described above for the measurement in plasma.

2.10. Statistical Analysis. Data are presented as the mean \pm standard deviation (SD). One-way analysis of variance (ANOVA) was used to determine significance among groups, after which post-hoc tests with the Bonferroni correction were used for comparison between individual groups. Statistical significance was established at $P<.05$. Nonparametric test ( 2 independence samples) was used to determine significance in Allergic reaction data. Statistical significance was established at $P<.05$.

\section{Results}

3.1. Characterization of the PTX Microemulsion. The PTX microemulsion concentrated solution was transparent and slightly yellow in color. The concentration of PTX in the microemuslion concentrated solution was $5 \mathrm{mg} / \mathrm{mL}$. The average particle size of the PTX microemulsion after the concentrated solution was diluted with $5 \%$ glucose infusion was approximately $142.4 \pm 1.2 \mathrm{~nm}$ with a polydispersity of $0.267 \pm 0.07$. The typical particle size and distribution is shown in Figure 1(a). TEM was used to examine the morphology of the PTX microemulsion (Figure 1(b)). The TEM images revealed that the PTX microemulsion were likely sphere in shape.

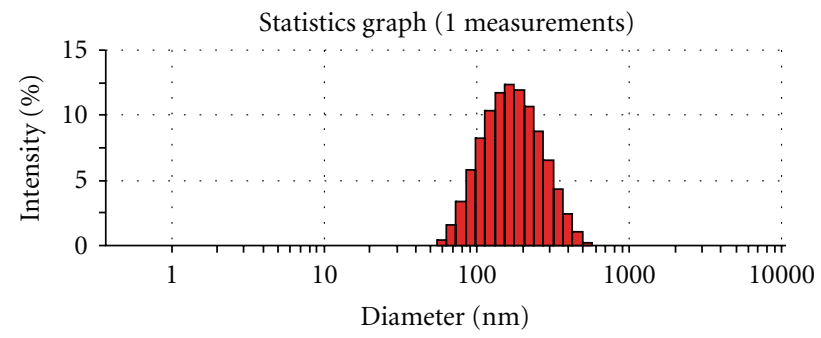

(a)

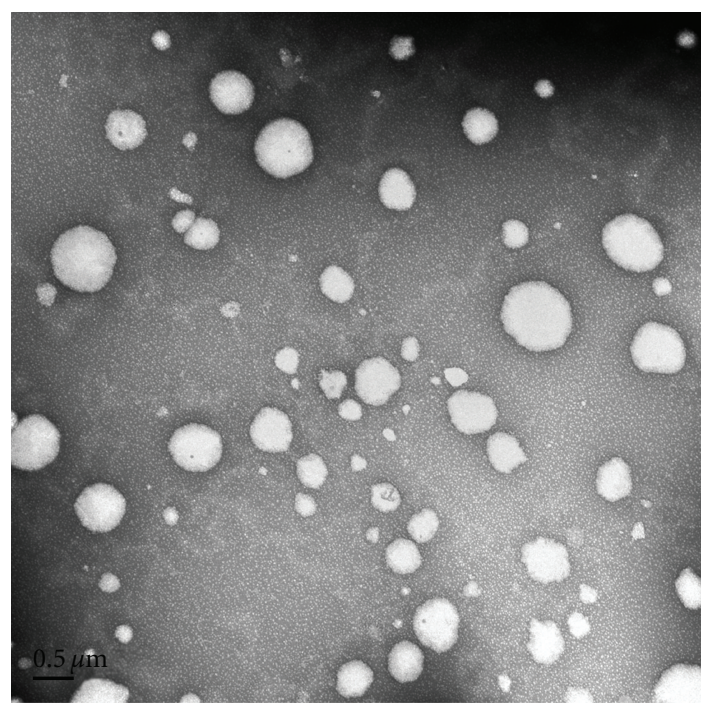

(b)

FIgUre 1: Typical particle size and distribution of the PTX microemulsion (a). Transmission electron micrograph of PTX microemulsion ((b), Bar $=0.5 \mu \mathrm{m})$.

3.2. Pharmacokinetics of the PTX Microemulsion after Intravenous Administration. The plasma concentration-time profiles of PTX after intravenous administration of the PTX formulations $(5 \mathrm{mg} / \mathrm{kg})$ were characterized in rats and illustrated in Figure 2. Data fitting was conducted and the result showed that the pharmacokinetic behavior of the PTX microemulsion and PTX injection fitted a twocompartment model. As shown in Figure 2, the curve for the PTX microemulsion group was similar to that of the PTX injection group. The main pharmacokinetic parameters of PTX are summarized in Table 2. As shown in Table 2, the values of $\mathrm{AUC}_{0-8}$ in the PTX microemulsion group and the PTX injection group were $3174.9 \pm 592.4$ and $3770.9 \pm$ $796.2 \mathrm{ng} \cdot \mathrm{h} / \mathrm{mL}$, respectively. There was no significant difference in $\mathrm{AUC}_{0-8}$ between these two groups. The bioavailability 
TABLE 2: The main pharmacokinetic parameters of PTX after intravenous administration of the PTX injection or microemulsion at $5 \mathrm{mg} / \mathrm{kg}$ PTX in SD rats (mean \pm S.D., $n=5$ ).

\begin{tabular}{|c|c|c|c|}
\hline Parameter & Units & PTX microemulsion & PTX injection \\
\hline$A$ & $\mathrm{ng} / \mathrm{mL}$ & $9245.8 \pm 3232.7$ & $9315.2 \pm 2601.7$ \\
\hline$B$ & $\mathrm{ng} / \mathrm{mL}$ & $1694.0 \pm 530.4$ & $1611.0 \pm 651.5$ \\
\hline$\alpha$ & $1 / \mathrm{h}$ & $5.934 \pm 2.40$ & $6.219 \pm 1.104$ \\
\hline$\beta$ & $1 / \mathrm{h}$ & $0.689 \pm 0.216$ & $0.837 \pm 0.139$ \\
\hline$t_{1 / 2 \alpha}$ & $\mathrm{h}$ & $0.134 \pm 0.057$ & $0.114 \pm 0.019$ \\
\hline$t_{1 / 2 \beta}$ & $\mathrm{h}$ & $1.074 \pm 0.279$ & $0.846 \pm 0.130$ \\
\hline$t_{1 / 2}$ & $\mathrm{~h}$ & $0.283 \pm 0.098$ & $0.278 \pm 0.064$ \\
\hline$K_{12}$ & $1 / \mathrm{h}$ & $2.393 \pm 1.197$ & $2.431 \pm 0.537$ \\
\hline$K_{21}$ & $1 / \mathrm{h}$ & $1.556 \pm 0.777$ & $2.035 \pm 0.421$ \\
\hline$K_{10}$ & $1 / \mathrm{h}$ & $2.674 \pm 0.826$ & $2.590 \pm 0.523$ \\
\hline $\mathrm{AUC}_{0-\infty}$ & $\mathrm{h} \mathrm{ng/mL}$ & $4141.7 \pm 787.6$ & $4671.1 \pm 981.6$ \\
\hline $\mathrm{Vc}$ & $\mathrm{mL} / \mathrm{kg}$ & $1242.0 \pm 385.4$ & $969.7 \pm 234.1$ \\
\hline $\mathrm{CL}$ & $\mathrm{mL} / \mathrm{h} / \mathrm{kg}$ & $1239.2 \pm 212.4$ & $1120.1 \pm 298.1$ \\
\hline
\end{tabular}

$A$ and $B$ : the hybrid parameters; $\alpha$ : distribution constant; $\beta$ : elimination constant; $t_{1 / 2 \alpha}$ : half-time of phase I; $t_{1 / 2 \beta}$ : half-time of phase II; $K_{21}:$ rate constant for drug leaving compartment 2 and passing into $1 ; K_{12}$ : rate constant for drug leaving compartment 1 and passing into 2 ; $K_{10}$ : elimination constant from the central compartment; $\mathrm{AUC}_{0-\infty}$ : area under the curve; $\mathrm{Vc}$ : apparent volume of distribution of the central compartment; CL: clearance from the twocompartment model.

TABLE 3: The $\mathrm{AUC}_{0-8}$ values of PTX after intravenous administration of the PTX injection or microemulsion at $5 \mathrm{mg} / \mathrm{kg}$ of PTX in $\mathrm{SD}$ rats (mean \pm S.D., $n=3$ ).

\begin{tabular}{lcc}
\hline & PTX microemulsion & PTX injection \\
\hline Liver & $54.84 \pm 9.10$ & $59.62 \pm 8.16$ \\
Kidney & $31.62 \pm 1.94$ & $34.49 \pm 2.56$ \\
Lung & $23.81 \pm 2.58$ & $27.48 \pm 3.97$ \\
Spleen & $23.13 \pm 2.05$ & $25.95 \pm 1.95$ \\
Heart & $13.10 \pm 1.05$ & $13.94 \pm 1.36$ \\
Ovaries & 15.20 & 16.58 \\
\hline
\end{tabular}

of PTX in the microemulsion group compared with that in the injection group was $84.2 \%$. Meanwhile, there was no significant difference in the main parameters between the PTX microemuslion group and the PTX injection group (Table 2).

3.3. Tissue Distribution of the PTX Microemulsion after Intravenous Administration. The tissue distribution profiles of PTX in the PTX microemulsion group and the PTX injection group were compared in rats. The concentration of PTX in each tissue was determined by HPLC analysis. As shown in Figure 3, PTX was widely and rapidly distributed into most tissues following intravenous administration of PTX formulations, and the highest concentration of PTX was found in liver, followed by kidney and lung at $0.167 \mathrm{~h}$ after administration. However, after $8 \mathrm{~h}$, the drug concentration rapidly decreased. The concentration of PTX in brain was undeterminable.

The AUC values in tissues are listed in Table 3. There was no significant difference in the tissue distribution of PTX between the PTX microemulsion group and the PTX injection group.

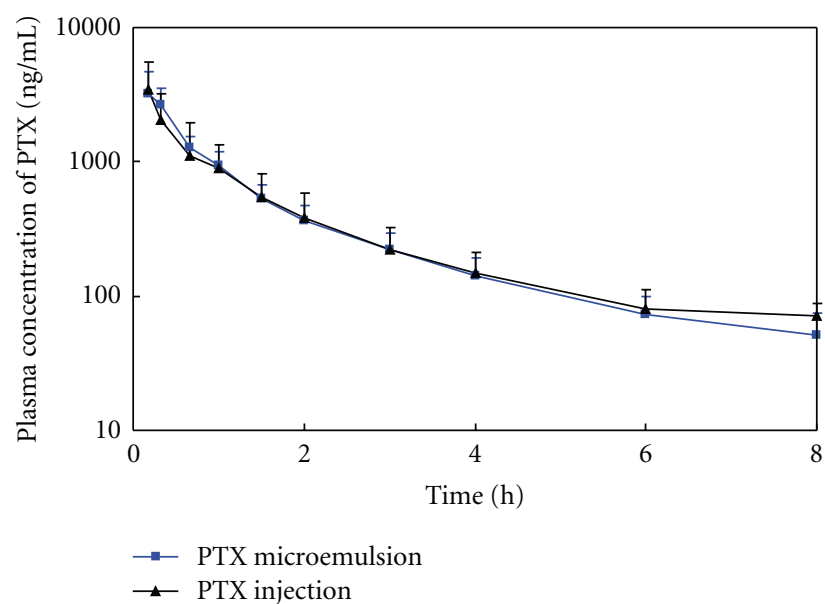

FIgUre 2: The plasma concentration-time profiles of PTX after intravenous administration of PTX microemulsion or PTX injection at $5 \mathrm{mg} / \mathrm{kg}$ PTX in SD rats (means \pm S.D., $n=5$ ).

3.4. In Vivo Antitumor Efficacy. The in vivo antitumor activity of the PTX microemulsion was investigated in OVCAR-3 and A549 tumor-bearing mice. As shown in Figures 4(a) and 4(b), PTX microemulsion markedly inhibited the growth of OVCAR-3 and A-549 tumors $(P<.01)$. A similar result was observed in the PTX injection treatment group $(P<.01)$. There was no significant difference in the antitumor activity between the microemulsion group and the injection group $(P>.05)$.

In the OVCAR-3 tumor-bearing mice groups, the mean tumor sizes at day 33 after implantation in the PTX injection, and the microemulsion group were $131 \pm 112$ and $63 \pm$ $49 \mathrm{~mm}^{3}$, respectively, compared with $690 \pm 206 \mathrm{~mm}^{3}$ in the control group $(P<.01)$. The corresponding tumor 
TABLE 4: The rank of allergic reactions for each dog.

\begin{tabular}{|c|c|c|c|c|c|}
\hline No. & $\begin{array}{l}\text { Control } \\
\text { group }\end{array}$ & $\begin{array}{l}\text { Paclitaxel injection } \\
\text { treatment group }\end{array}$ & $\begin{array}{c}\text { Paclitaxel microemulsion } \\
\text { treatment group }\end{array}$ & $\begin{array}{c}\text { Paclitaxel injection } \\
\text { premedication treatment group }\end{array}$ & $\begin{array}{c}\text { Paclitaxel microemulsion } \\
\text { premedication treatment group }\end{array}$ \\
\hline 1 & - & +++ & ++ & ++ & + \\
\hline 2 & - & +++ & ++ & ++ & + \\
\hline 3 & - & +++ & ++ & ++ & + \\
\hline 4 & - & +++ & ++ & ++ & + \\
\hline 5 & - & +++ & ++ & ++ & + \\
\hline 6 & - & +++ & $\begin{array}{l}+++ \\
* *\end{array}$ & $\begin{array}{l}+++ \\
* * \neq \neq\end{array}$ & $\begin{array}{c}+ \\
++\S \S\end{array}$ \\
\hline
\end{tabular}

$* * P<.01$, Paclitaxel injection treatment group versus Paclitaxel microemulsion treatment group or Paclitaxel injection premedication treatment group. $\neq \ddagger P>.05$, Paclitaxel microemulsion treatment group versus Paclitaxel injection premedication treatment group.

$\dagger \dagger P<.01$, Paclitaxel microemulsion treatment group versus Paclitaxel microemulsion premedication treatment group.

$\S \S P<.01$, Paclitaxel injection premedication treatment group versus Paclitaxel microemulsion premedication treatment group.

growth inhibition in the PTX injection group and in the PTX microemulsion treated group was $81.0 \%$ and $90.9 \%$, respectively. Similar results were also observed in the A 549 tumor-bearing mice groups, the mean tumor sizes at day 32 after implantation in the PTX injection group and the microemulsion group were $659 \pm 228$ and $528 \pm$ $316 \mathrm{~mm}^{3}$, respectively, compared with $1746 \pm 520 \mathrm{~mm}^{3}$ in the control group $(P<.01)$. The corresponding tumor growth inhibition in the PTX injection group and in the PTX microemulsion group was $62.3 \%$ and $69.7 \%$, respectively.

As shown in Figures 5(a) and 5(b), the average tumor weight in the $5 \%$ glucose infusion, PTX injection, and PTX microemulsion groups at day 33 after OVCAR-3 cell implantation was $362 \pm 105,76 \pm 94$, and $40 \pm 59 \mathrm{mg}$, respectively. The average tumor weight in the $5 \%$ glucose infusion, PTX injection and PTX microemulsion groups at day 32 after A 549 cell implantation was $927 \pm 286,353 \pm 142$, and $268 \pm 143 \mathrm{mg}$, respectively.

There was no significant difference in body weight among the PTX microemulsion group, PTX injection group, and control group (data not shown).

3.5. Injection Safety. Hemolysis test: complete hemolysis was observed in the positive control tube at $15 \mathrm{~min}$, the solution was red clearly diaphanous, and no erythrocytes survived at the bottom of the tube. The erythrocytes were precipitated at the bottom of the other six tubes and dispersed after shaking, while the supernatant was achromatic and transparent over the observation period of $4 \mathrm{~h}$. These results demonstrated that the PTX microemulsion at a concentration of $1 \mathrm{mg} / \mathrm{mL}$ did not cause hemolysis and erythrocyte agglutination at $37^{\circ} \mathrm{C}$.

Intravenous irritation: after a 3-day administration of pacltaxel microemulsion, 5\% glucose infusion, no erythema, and edema were observed at the injection sites. The histopathologic examination of the rabbit ear-border vein indicated that the vessel wall and endothelial cell structures were unimpaired. Furthermore, no angiectasia and thrombus formation was observed in the lumen of the vein. There were no significant pathological changes, inflammatory cell infiltrate, hemorrhage epimorphosis, and necrosis in the vessel walls and surrounding tissues. The histopathologic examination results of the ears from rabbits given the microemulsion were similar to those of the control group. All the results demonstrated that PTX microemulsion at a dose of $5 \mathrm{mg} / \mathrm{kg}$ produced no irritation of the rabbit ear veins.

Allergic reaction: the ranking of the allergic reactiona is shown in Table 4. In the PTX injection group, the rank of the allergic reaction was Grade 3/+++ in all animals (6/6). Most animals in the PTX microemulsion group (5/6) and the PTX injection premedication group (5/6) experienced Grade $2 /++$. The rank of the allergic reaction in the PTX microemulsion premedication group was Grade 1/+ (6/6). In the control group, the allergic reaction ranking was negative. The main observed allergic reactions were transient flushing and rash, licking the nose, drowsiness, rash, angioedema, mucous membrane hyperemia, vomiting, gatism, mania, and dyspnea. The allergic reaction in paclitaxel injection treatment group was significantly serious than that in PTX microemulsion treatment groups or paclitaxel injection premedication treatment groups $(P<.01)$. Similar results were also found in PTX microemulsion treatment group versus PTX microemulsion premedication treatment group $(P<.01)$ or paclitaxel injection premedication treatment group versus PTX microemulsion premedication treatment group $(P<.01)$. There were no significant differences observed in PTX microemulsion treatment group versus paclitaxel injection premedication treatment group $(P>$ .05). After administration of PTX formulations, the body weight decreased slightly compared with that of the control group and but gradually returned to normal during the observation phase. A similar phenomenon was also observed for the white blood count and platelet count. There was no significant difference in toxic signs among the PTX formulation groups.

\section{Discussion}

The commercially available PTX injection is a clear to colorless formulation supplied in $5 \mathrm{~mL}$ vials containing PTX $6 \mathrm{mg} / \mathrm{mL}$, CrEL $527 \mathrm{mg} / \mathrm{mL}$, and dehydrated ethanol $396 \mathrm{mg} / \mathrm{mL}$. Therefore, the amounts of PTX, CrEL, and dehydrated ethanol in a vial of PTX injection are $30 \mathrm{mg}$, 

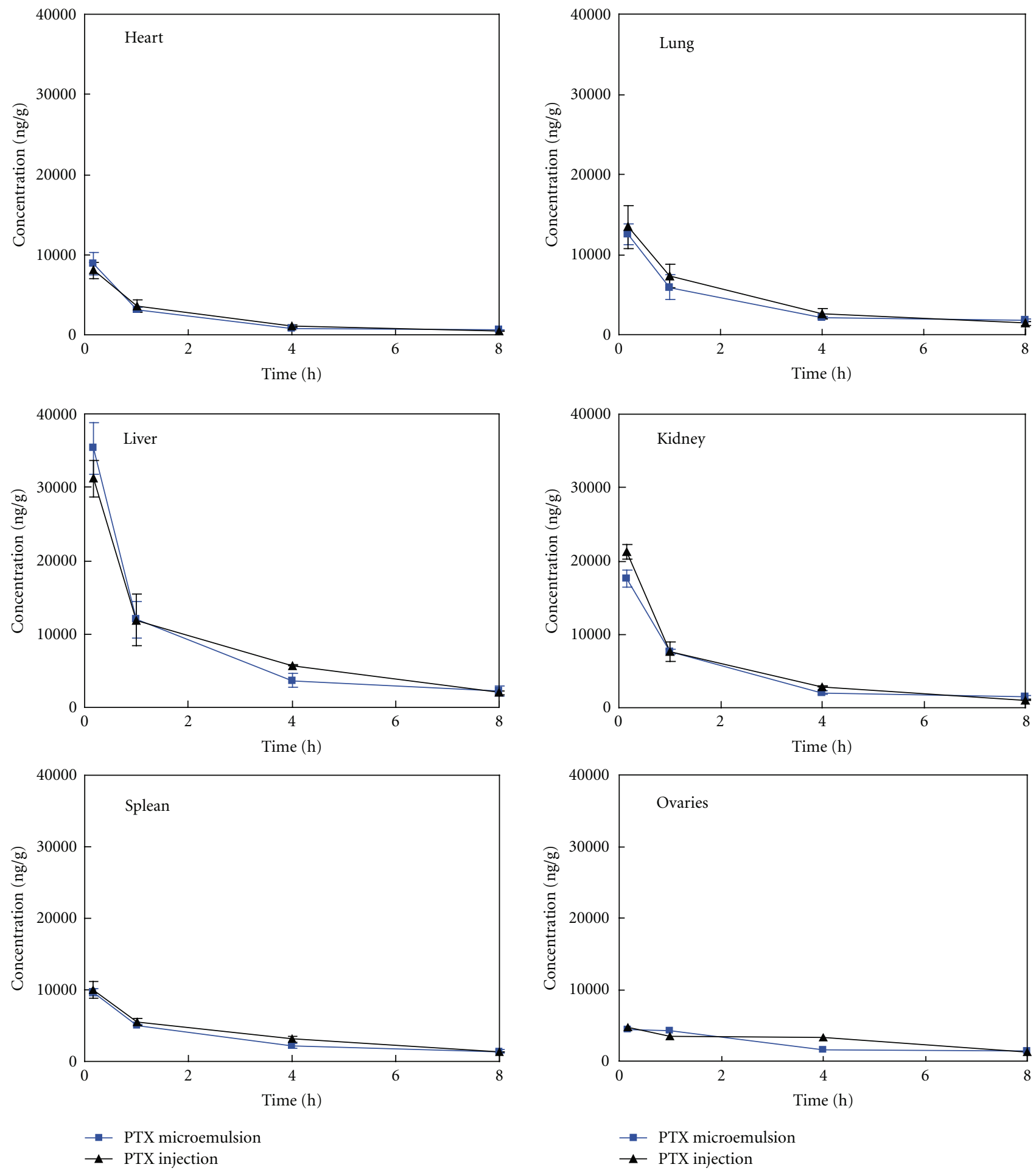

FIGURE 3: The tissue distribution profiles of PTX in PTX microemulsion and PTX injection after intravenous administration of PTX microemulsion or PTX injection at $5 \mathrm{mg} / \mathrm{kg}$ PTX in SD rats (means \pm S.D., $n=5$ ).

$2.6 \mathrm{~g}$ and $2.4 \mathrm{~g}$, respectively. The amount of CrEL in the PTX microemulsion concentrated solution was markedly reduced compared with that in the PTX injection (from $2.6 \mathrm{~g}$ to $0.8 \mathrm{~g}$ ). When this microemulsion concentrated solution was diluted with 5\% glucose infusion, the particle size of the formed PTX microemulsion was about $150 \mathrm{~nm}$.
In the present study, we initially evaluated the pharmacokinetics and biodistribution of PTX in the microemulsion. The curve of PTX in the microemulsion group was similar to that in the PTX injection group (Figure 2). The AUC value in the PTX microemulsion group was slightly lower than that in the PTX injection group. This was due to the CrEL which 
increased the concentration of PTX in plasma [23]. The tissue distribution profiles of PTX in the PTX microemulsion and the injection groups were compared in rats. There were no significant differences in PTX in the main tissues between the microemulsion group and the injection group (Figure 3 and Table 3). These results indicate that the pharmacokinetic and distribution properties of PTX in the microemulsion were similar to those in the PTX injection. In addition, the toxic effect of PTX microemulsion to mice or rats will be further investigated in future since the pharmacokinetics behaviors of PTX may be influenced by the toxicity of its vehicles.

It has been reported that PTX is commonly used to treat ovarian, breast, and nonsmall cell lung cancers [24]. In the present study, we selected a human ovarian cancer cell line (OVCAR-3) and a human nonsmall cell lung cancer cell line (A 549) as animal tumor models. The in vivo antitumor studies indicated that the antitumor efficacy of the PTX microemulsion in OVCRA-3 and A 549 tumor-bearing animals was similar to that of the PTX injection (Figures 4 and 5).

The results of injection safety test of the PTX microemulsion indicated that the PTX microemulsion did not cause hemolysis, erythrocyte agglutination, and simulative reactions, showing that it was safe to inject.

The allergic reaction studies showed that all animals in the PTX formulation treatment groups experienced allergic reactions, but to a varying degree. The allergic reactions in the PTX microemulsion premedication group were not as severe as those in the PTX injection premedication group $(P<.01)$. Also, the allergic reactions in the PTX microemulsion group were milder than those in the PTX injection group $(P<.01)$, similar to those in the PTX injection premedication group. It has been reported that CrEL and its formulated micelles can cause allergic reactions $[25,26]$ and dogs are known to be particularly sensitive to agents that cause allergic reactions [25, 27]. Therefore, in the present study, we chose beagle dogs as an animal model to evaluating the allergic reactions caused by PTX formulations. Due to the amount of CrEL necessary to deliver the required doses of cyclosporine or teniposide being much lower than that in the PTX injection, the reported side effects linked with CrEL are limited [28, 29]. Considering the formulation of the present PTX microemulsion, the amount of CrEL was markedly reduced compared with that in the PTX injection $(0.8 \mathrm{~g}$ in microemulsion versus $2.6 \mathrm{~g}$ in injection). Our allergic reaction results indicated that the incidence and degree of allergic reactions in the PTX microemulsion group, with or without premedication, were significantly lower than those in the PTX injection group. Similar results were also observed in guinea pigs (data not shown), indicating that the potential allergic reaction induced by PTX microemulsion was significantly decreased compared with that in Taxol. Therefore, we suggest that this PTX microemulsion containing less CrEL significantly reduces the allergic side effects associated with CrEL.

Now, this PTX microemulsion concentration solution has been approved for phase I trials by the China State Food and Drug Administration (no. 2010L01157). The antitumor

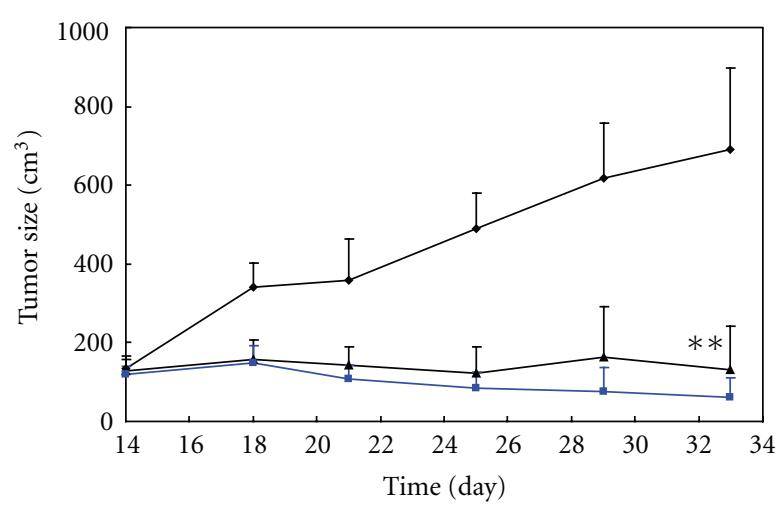

(a)

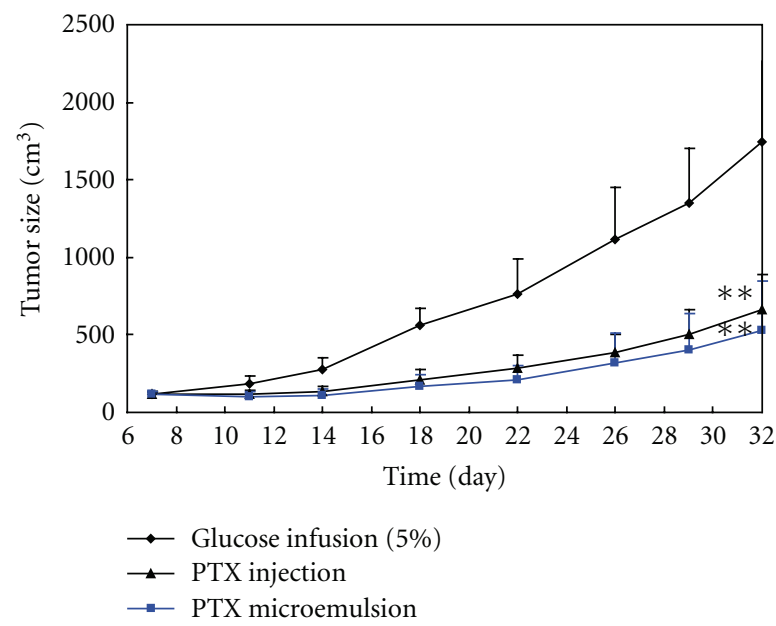

(b)

FIgURE 4: Tumor growth inhibition by PTX injection or PTX microemulsion. BALB/C mice were inoculated s.c. with OVCAR3 cells (a) or A-549 cells (b) and treated with 5\% glucose, PTX injection or PTX microemulsion $(15 \mathrm{mg} / \mathrm{kg}$, i.v., q4d4, every 4 days for four doses), respectively. Tumor size was measured with calipers twice per week. Results are given as means \pm S.D. $(n=6) .{ }^{* *} P<.01$ versus $5 \%$ glucose infusion as control.

efficacy and safety of the PTX microemulsion will now be further evaluated in volunteers.

\section{Conclusion}

In summary, a novel PTX microemulsion delivery system containing a reduced amount of CrEL was developed and characterized as an effective alternative to commercially available PTX injection. The PTX microemulsion had similar pharmacokinetic and antitumor efficacy to the PTX injection, but significantly reduced the allergic reactions caused by CrEL. These results indicate that PTX microemulsion overcomes the disadvantages of conventional PTX injection and is one possible approach to avoid the limitations of the current injection product and to produce a desirable therapeutic efficacy. 


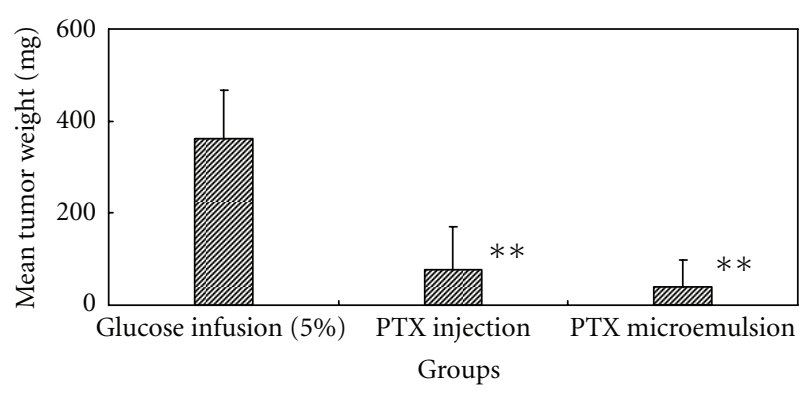

(a)

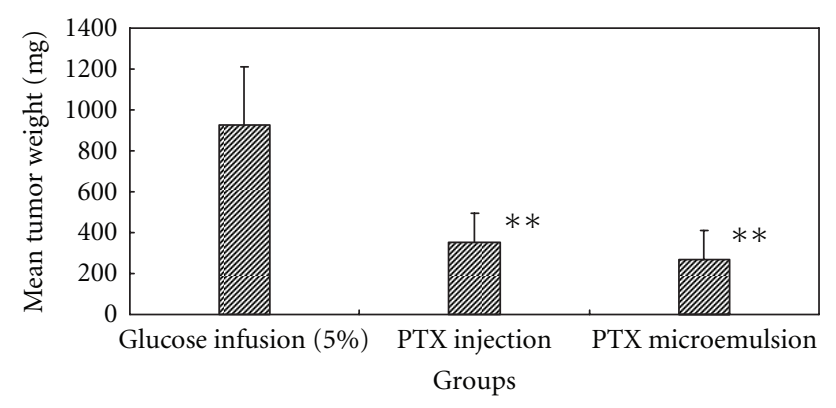

(b)

FIgure 5: The mean tumor weight in the $5 \%$ glucose infusion, PTX injection and PTX microemulsion groups at day 33 after OVCAR3 cell implantation (a) or A-549 cells (b) at day 32 after A 549 cell implantation. Results are given as means \pm S.D. $(n=6) .{ }^{* *} P<.01$ versus $5 \%$ glucose infusion as control.

\section{Acknowledgments}

The authors gratefully acknowledge the financial support from the National Natural Science Foundation of China (no. 30873170) and the National Basic Research Program of China (973 Program nos. 2007CB935800 and 2009CB930300).

\section{References}

[1] E. K. Rowinsky, L. A. Cazenave, and R. C. Donehower, "Taxol: a novel investigational antimicrotubule agent," Journal of the National Cancer Institute, vol. 82, no. 15, pp. 1247-1259, 1990.

[2] H. Gelderblom, J. Verweij, K. Nooter, and A. Sparreboom, "Cremophor EL: the drawbacks and advantages of vehicle selection for drug formulation," European Journal of Cancer, vol. 37, no. 13, pp. 1590-1598, 2001.

[3] J. Szebeni, C. R. Alving, S. Savay et al., "Formation of complement-activating particles in aqueous solutions of Taxol: possible role in hypersensitivity reactions," International Immunopharmacology, vol. 1, no. 4, pp. 721-735, 2001.

[4] E. K. Rowinsky, E. A. Eisenhauer, V. Chaudhry, S. G. Arbuck, and R. C. Donehower, "Clinical toxicities encountered with paclitaxel (TAXOL)," Seminars in Oncology, vol. 20, no. 4, pp. $1-15,1993$.

[5] R. B. Weiss, R. C. Donehower, P. H. Wiernik et al., "Hypersensitivity reactions from taxol," Journal of Clinical Oncology, vol. 8, no. 7, pp. 1263-1268, 1990.

[6] E. A. Eisenhauer, W. W. ten Bokkel Huinink, K. D. Swenerton et al., "European-Canadian randomized trial of paclitaxel in relapsed ovarian cancer: high-dose versus low-dose and long versus short infusion," Journal of Clinical Oncology, vol. 12, no. 12, pp. 2654-2666, 1994.

[7] S. Singh and A. K. Dash, "Paclitaxel in cancer treatment: perspectives and prospects of its delivery challenges," Critical Reviews in Therapeutic Drug Carrier Systems, vol. 26, no. 4, pp. 333-372, 2009.

[8] T. Y. Kim, D. W. Kim, J. Y. Chung et al., "Phase I and pharmacokinetic study of Genexol-PM, a Cremophor-free, polymeric micelle-formulated paclitaxel, in patients with advanced malignancies," Clinical Cancer Research, vol. 10, no. 11, pp. 3708-3716, 2004.

[9] D. W. Kim, S. Y. Kim, H. K. Kim et al., "Multicenter phase II trial of Genexol-PM, a novel Cremophor-free, polymeric micelle formulation of paclitaxel, with cisplatin in patients with advanced non-small-cell lung cancer," Annals of Oncology, vol. 18, no. 12, pp. 2009-2014, 2007.

[10] A. C. Mita, A. J. Olszanski, R. C. Walovitch et al., "Phase I and pharmacokinetic study of AI-850, a novel microparticle hydrophobic drug delivery system for paclitaxel," Clinical Cancer Research, vol. 13, no. 11, pp. 3293-3301, 2007.

[11] T. C. Chao, Z. Chu, L. M. Tseng et al., "Paclitaxel in a novel formulation containing less Cremophor EL as firstline therapy for advanced breast cancer: a phase II trial," Investigational New Drugs, vol. 23, no. 2, pp. 171-177, 2005.

[12] T. E. Stinchcombe, "Nanoparticle albumin-bound paclitaxel: a novel Cremphor-EL-free formulation of paclitaxel," Nanomedicine, vol. 2, no. 4, pp. 415-423, 2007.

[13] S. Talegaonkar, A. Azeem, F. J. Ahmad, R. K. Khar, S. A. Pathan, and Z. I. Khan, "Microemulsions: a novel approach to enhanced drug delivery," Recent Patents on Drug Delivery and Formulation, vol. 2, no. 3, pp. 238-257, 2008.

[14] R. P. Bagwe, J. R. Kanicky, B. J. Palla, P. K. Patanjali, and D. O. Shah, "Improved drug delivery using microemulsions: rationale, recent progress, and new horizons," Critical Reviews in Therapeutic Drug Carrier Systems, vol. 18, no. 1, pp. 77-140, 2001.

[15] M. J. Lawrence and G. D. Rees, "Microemulsion-based media as novel drug delivery systems," Advanced Drug Delivery Reviews, vol. 45, no. 1, pp. 89-121, 2000.

[16] I. Malina and A. Radomska-Soukharev, "Microemulsions with timolol as potential eye drops," Pharmazie, vol. 61, no. 7, pp. 650-651, 2006.

[17] A. O. Nornoo, D. W. Osborne, and D. S. L. Chow, "Cremophor-free intravenous microemulsions for paclitaxel. I: formulation, cytotoxicity and hemolysis," International Journal of Pharmaceutics, vol. 349, no. 1-2, pp. 108-116, 2008.

[18] A. O. Nornoo and D. S. L. Chow, "Cremophor-free intravenous microemulsions for paclitaxel. II. Stability, in vitro release and pharmacokinetics," International Journal of Pharmaceutics, vol. 349, no. 1-2, pp. 117-123, 2008.

[19] K. L. Hennenfent and R. Govindan, "Novel formulations of taxanes: a review. Old wine in a new bottle?" Annals of Oncology, vol. 17, no. 5, pp. 735-749, 2006.

[20] L. He, G. L. Wang, and Q. Zhang, "An alternative paclitaxel microemulsion formulation: hypersensitivity evaluation and pharmacokinetic profile," International Journal of Pharmaceutics, vol. 250, no. 1, pp. 45-50, 2003.

[21] V. J. Poirier, A. E. Hershey, K. E. Burgess et al., "Efficacy and toxicity of paclitaxel (Taxol) for the treatment of canine malignant tumors," Journal of Veterinary Internal Medicine, vol. 18, no. 2, pp. 219-222, 2004.

[22] X. R. Liu, KE. C. Wu, Y. Huang et al., "In vitro and in vivo studies on plasma-to-blood ratio of paclitaxel in human, 
rabbit and rat blood fractions," Biological and Pharmaceutical Bulletin, vol. 31, no. 6, pp. 1215-1220, 2008.

[23] H. Gelderblom, K. Mross, A. J. ten Tije et al., "Comparative pharmacokinetics of unbound paclitaxel during 1- and 3-hour infusions," Journal of Clinical Oncology, vol. 20, no. 2, pp. 574$581,2002$.

[24] J. Crown and M. O'Leary, “The taxanes: an update," The Lancet, vol. 355, no. 9210, pp. 1176-1178, 2000.

[25] J. Szebeni, F. M. Muggia, and C. R. Alving, "Complement activation by Cremophor EL as a possible contributor to hypersensitivity to paclitaxel: an in vitro study," Journal of the National Cancer Institute, vol. 90, no. 4, pp. 300-306, 1998.

[26] J. Szebeni, C. R. Alving, L. Rosivall et al., "Animal models of complement-mediated hypersensitivity reactions to liposomes and other lipid-based nanoparticles," Journal of Liposome Research, vol. 17, no. 2, pp. 107-117, 2007.

[27] M. Ennis, W. Lorenz, and B. Kapp, "Comparison of the histamine-releasing activity of cremophor E1 and some of its derivatives in two experimental models: the in vivo anaesthetized dog and in vitro rat peritoneal mast cells," Agents and Actions, vol. 16, no. 3-4, pp. 265-268, 1985.

[28] D. L. Howrie, R. J. Ptachcinski, and B. P. Griffith, "Anaphylactoid reactions associated with parenteral cyclosporine use: possible role of Cremophor EL," Drug Intelligence and Clinical Pharmacy, vol. 19, no. 6, pp. 425-427, 1985.

[29] P. J. O'Dwyer, S. A. King, C. L. Fortner, and B. LeylandJones, "Hypersensitivity reactions to teniposide (VM-26): an analysis," Journal of Clinical Oncology, vol. 4, no. 8, pp. 1262$1269,1986$. 

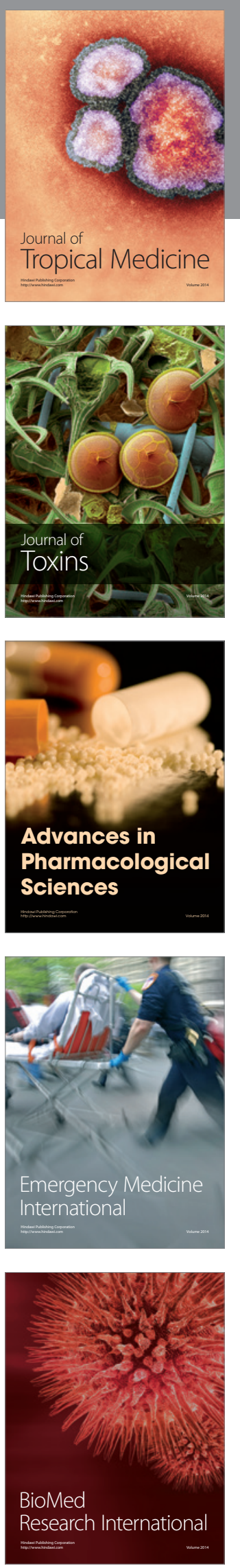
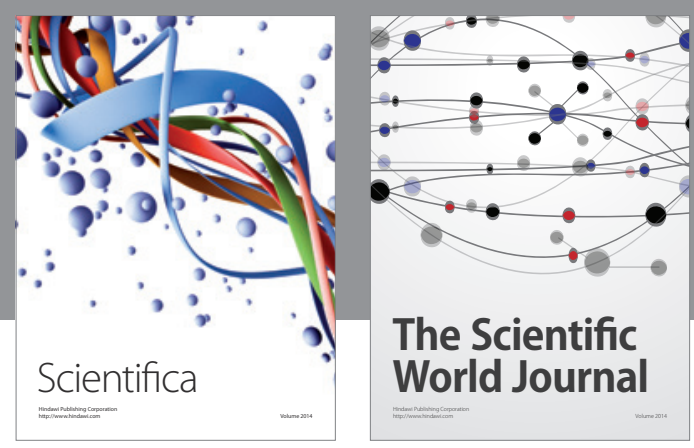

The Scientific World Journal
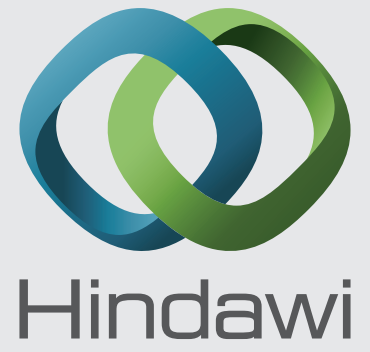

Submit your manuscripts at

http://www.hindawi.com
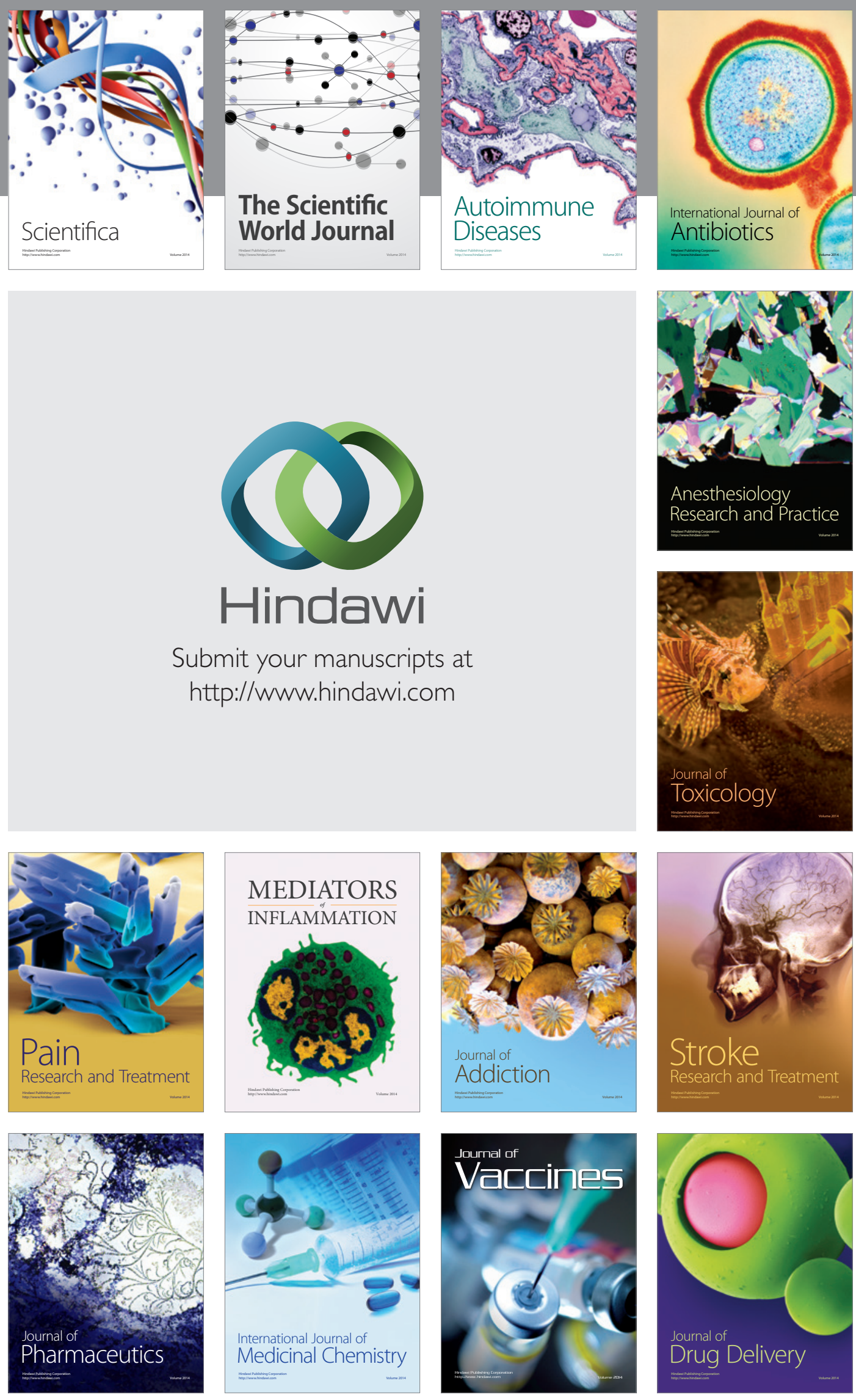